\title{
Prescribing and testing by primary care providers to assess adherence to the Choosing Wisely Canada recommendations: a retrospective cohort study
}

\author{
Alexander Singer MB BAO BCh, Leanne Kosowan MSc, Alan Katz MB ChB MSc, \\ Kheira Jolin-Dahel MSc MD, Karen Appel MD, Lisa M. Lix PhD
}

Abstract

Background: Choosing Wisely Canada is an initiative to reduce overprescribing and overtesting. This study assessed adherence to 4 Choosing Wisely Canada recommendations for interventions commonly performed in primary care: (a) antibiotic prescriptions for infections that are probably viral in origin, (b) routine vitamin D tests in low-risk adults, (c) annual screening blood tests and (d) prescriptions of antipsychotic medication to treat symptoms of dementia.

Methods: We conducted a retrospective cohort study of data from the electronic medical records of patients who had an encounter between 2014 and 2016 with a participating Manitoba Primary Care Research Network primary care provider in Manitoba, Canada. Patient encounter data were reviewed for prescribing and testing practices. Descriptive statistics and multivariable models assessed associations between patient and provider characteristics and rates of prescribing and testing.

Results: Data for 164195 patients from 230 providers were included in the study. Sixteen percent $(n=25629)$ of patients had an encounter that involved potentially unnecessary diagnostic testing and treatment. A minority of providers contributed to above-average rates of prescribing and testing: $29 \%(n=69)$ of providers prescribed antibiotics for a viral indication, $11 \%(n=24)$ prescribed an antipsychotic to a patient diagnosed with dementia, $9 \%(n=24)$ ordered prostate-specific antigen tests and $14 \%(n=34)$ ordered vitamin $\mathrm{D}$ tests at above-average rates, respectively. Patient and provider characteristics were associated with each of the prescribing and testing practices assessed.

Interpretation: This study demonstrated that fewer than $30 \%$ of primary care providers contributed to interventions in direct contradiction to Choosing Wisely Canada recommendations. Improvement strategies specific to each prescription or testing recommendation should target specific providers to prevent patient harm and reduce unnecessary health care spending.

$\mathrm{F}$ vidence suggests that $20 \%-30 \%$ of total health care spending is associated with unnecessary care. ${ }^{1-4} \mathrm{In}$ 2014, the Choosing Wisely Canada campaign launched, encouraging patients and providers to reduce nonrecommended interventions. ${ }^{5}$ Choosing Wisely Canada promotes recommendations developed by professional societies from 47 different specialties. ${ }^{5}$ The recommendations relevant to primary care relate to judicious prescribing and laboratory testing to reduce harm or interventions that do not benefit patients. Two recommendations related to prescribing practices are about unnecessary prescribing of antibiotic ${ }^{6}$ and antipsychotic ${ }^{7}$ medication. Viral illnesses (e.g., acute sinusitis, bronchitis) do not respond to antibiotic treatment. Unnecessary prescribing of antibiotics puts patients at risk of adverse events, including allergic reactions and increased bacterial resistance. ${ }^{6,8-12}$ Similarly, there is strong evidence demonstrating that antipsychotics should be used judiciously for the treatment of behavioural and psychological symptoms of dementia; they can increase the risk of premature death and adverse events such as cardiovascular effects.,13-16

Competing interests: Alexander Singer reports receiving a grant from the Manitoba Medical Services Foundation during the conduct of the study. No other competing interests were declared.

This article has been peer reviewed.

Correspondence to: Leanne Kosowan, leanne.kosowan@umanitoba.ca

CMAJ Open 2018. DOI:10.9778/cmajo.20180053 
Unwarranted laboratory testing exposes patients to specific harms such as false-positive results, undue anxiety and costly follow-up investigations, all of which lead to unnecessary costs for the health system. ${ }^{6,17-20}$ For example, an annual screening blood test performed in primary care, the prostate-specific antigen test, is associated with only a modest reduction in cancer mortality and with adverse effects (e.g., urinary incontinence, bleeding and infection). ${ }^{18-20}$ Additionally, in northern climates vitamin D supplementation is routinely recommended; ${ }^{6,17,21-25}$ therefore, testing of vitamin D levels is recommended only in high-risk patients. ${ }^{21-24}$

In light of this evidence, this study aims to assess adherence to these 4 Choosing Wisely Canada recommendations: (a) don't prescribe antibiotics for viral upper respiratory tract infections, ${ }^{6}(\mathrm{~b})$ don't prescribe antipsychotics as first choice to treat symptoms of dementia, ${ }^{7}$ (c) don't routinely measure vitamin D in low-risk adults ${ }^{6}$ and (d) don't do annual screening blood tests unless directly indicated by the patient's risk profile. ${ }^{6}$ When performed routinely these interventions provide limited benefit, and they are associated with patient harm and high costs to the system. ${ }^{6-25}$ Reliable data on these 4 interventions were available within the Manitoba Primary Care Research Network repository. We used this database to understand how frequently these interventions are performed in participating primary care practices and what factors are associated with potentially unnecessary care.

\section{Methods}

We conducted a retrospective cohort study using electronic medical record (EMR) data from the Manitoba Primary Care Research Network, a network within the Canadian Primary Care Sentinel Surveillance Network. The Canadian Primary Care Sentinel Surveillance Network is the largest multisystem database in Canada to extract and process de-identified data from the EMRs of consenting primary care providers quarterly to build a pan-Canadian EMR-based repository for health surveillance. Data were extracted from the EMRs of 239 providers in 46 practices. All patients who had at least 1 encounter between 2014 and 2016 with a participating Manitoba Primary Care Research Network primary care provider were included in the study.

\section{Assessment of prescribing practices}

Patients with an antibiotic prescription (anatomical therapeutic chemical [ATC] classification system code $\mathrm{J} 01^{*}$ ) were assessed for an encounter with a viral indication, within 7 days of the prescription. We used the following codes of the International Classification of Diseases, 9th Revision (Clinical Modification) (ICD-9-CM) to indicate a diagnosis of a viral upper respiratory tract infection: 461 (acute mild-to-moderate sinusitis), 465 (upper respiratory tract infection), 466 (bronchitis), 460 (acute rhinitis), 464 (acute laryngitis and tracheitis), 477 (nasopharyngitis) or 487/488 (influenza). Antipsychotic prescribing (ATC: N05A) practices were assessed among patients 65 years or older with a diagnosis of dementia (ICD-9-CM: 290*, 294* and $331^{*}$ ) in the problem list of their EMR.

\section{Assessment of laboratory testing}

We chose the prostate-specific antigen (PSA) test as a representative example of an annual screening blood test frequently ordered in primary care. The Manitoba Primary Care Research Network extracts designated laboratory tests from the EMRs of participating providers, providing a laboratory test name. The laboratory records were assessed for patients who had a PSA or vitamin D test recorded in the EMR.

\section{Data analysis}

We report descriptive analytics on the use of the nonrecommended diagnostic tests and treatments, and separate multivariable logistic models for each of the Choosing Wisely Canada recommendations relating to (a) prescription of antibiotics for viral infections, ${ }^{6}$ (b) prescription of antipsychotics in patients with dementia, ${ }^{7}$ (c) vitamin D level testing ${ }^{6}$ or (d) annual blood screening (PSA) testing. ${ }^{6}$ Scatter plots assessed frequency of treatment per provider, ranked according to patient complexity. Patients with a greater number of diagnosed comorbidities were considered more complex than patients with no diagnosed comorbidities. The multivariable logistic models with generalized estimating equations assessed associations between prescribing and testing, and characteristics of patients (sex, age, comorbidities, frequency of office visits), providers (type, age, sex, average number of encounters a week) and practices (location, size, funding model) as recorded in the EMR. The models also accounted for the number of encounters with each provider; some providers had significantly more patients in their practice than other providers. Patient age was categorized on the basis of the outcome variable. The Canadian Task Force on Preventive Health Care strongly recommends against screening asymptomatic men younger than 55 years and older than 70 years with PSA serum testing. ${ }^{18}$ For men between the ages of 55 and 70 years, there is a weak recommendation to not test for prostate cancer with PSA. ${ }^{19}$ In our study, men aged 55-70 years were compared with men of all other ages for a PSA test. Patient age when the vitamin D test was ordered increased by 10 -year increments. Antibiotic prescriptions were assessed between patients younger than 60 years and patients 60 years of age or older. Numbers of diagnosed comorbidities were grouped as follows: 0,1 or 2 , and 3 or more comorbidities. Within the antipsychotic prescribing model a diagnosis of dementia was not considered a comorbidity.

\section{Ethics approval}

Approval for this study was obtained from the Health Research Ethics Board at the University of Manitoba (HS19281 [H2016:022]).

\section{Results}

Between 2014 and 2016, 164195 patients had at least 1 encounter with a participating Manitoba Primary Care Research Network primary care provider (Table 1). Sixteen percent $(n=25629)$ of these patients had at least 1 encounter that had an outcome contrary to one of the Choosing Wisely 


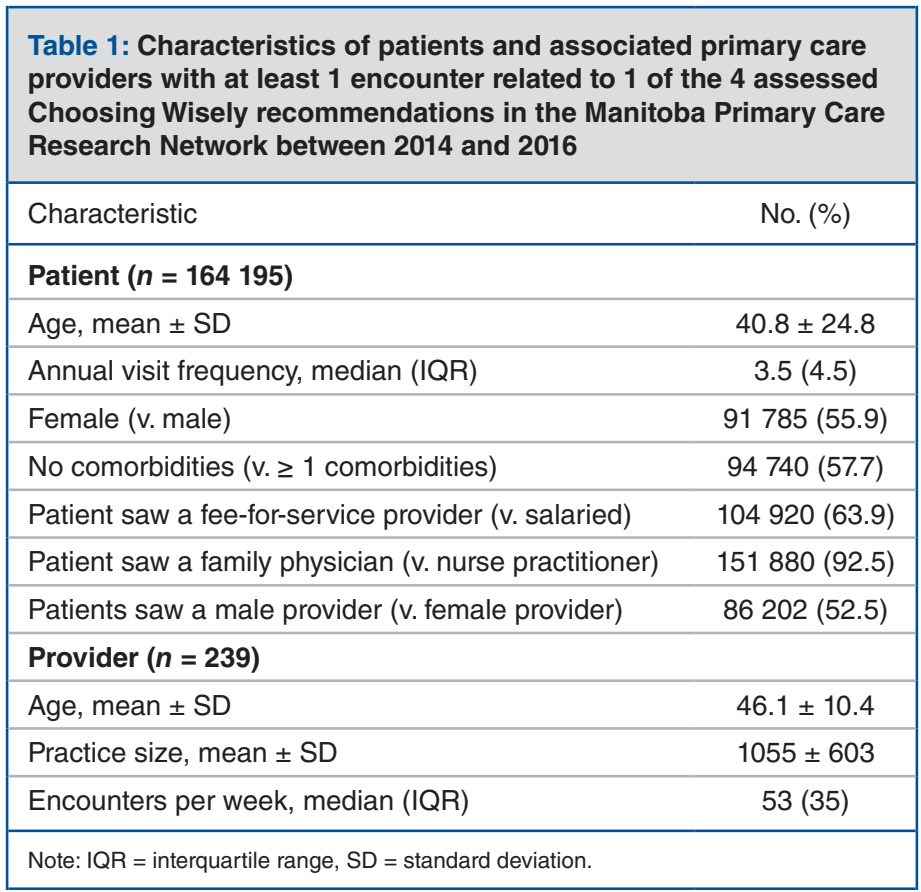

Canada recommendations we evaluated. Specifically, $65.3 \%$ of the patients with an encounter outcome contrary to a Choosing Wisely Canada recommendation were prescribed an antibiotic for a viral infection, $28.7 \%$ received a PSA test and $9.0 \%$ had a vitamin D screen, and among patients with a diagnosis of dementia, $17.0 \%$ had been prescribed an antipsychotic medication.

\section{Prescribing practices}

There were 16742 patients (15.6\% of 164195$)$ who were prescribed an antibiotic in visits associated with a viral diagnosis. On average, providers prescribed antibiotics to treat viral infections in $4.4 \%$ of the patients within their practice, equating to 11 prescriptions per year, per provider.

There were 3372 patients aged 65 years or older with a diagnosis of dementia. Among patients diagnosed with dementia, 573 patients $(17.0 \%)$ received a prescription for an antipsychotic medication. There were 214 providers with at least 1 patient diagnosed with, or billed for, dementia. On average, providers prescribed an antipsychotic prescription to $14.3 \%$ of patients with dementia.

Sixty-nine providers (29\%) were responsible for most of the potentially unnecessary antibiotic prescribing $(>10 \%$ of patients in their practice). Seven providers (3\%) prescribed antibiotics to treat a viral infection in more than $35 \%$ of the patients in their practice ( $n=1686$ patients) annually. Similarly, there were 24 providers $(11 \%)$ who prescribed antipsychotics to more than $36 \%$ of the patients diagnosed with dementia in their practice ( $n=109$ patients). Figure 1 shows that although both antibiotic and antipsychotic prescribing increased among physicians with more complex patients, different providers contributed to the high prescribing in each cohort.
Patients with 3 or more comorbidities had higher odds of receiving a potentially unnecessary prescription than patients with no comorbidities. However, patients under 60 years of age were 1.19 times more likely to receive antibiotics than patients 60 years of age or older ( $95 \%$ confidence interval [CI] 1.02-1.38) (Table 2). All other patient and provider factors associated with prescribing rates were dependent on the prescription type. For example, female patients had 1.22 times higher odds (95\% CI 1.15-1.30) of receiving an antibiotic prescription for a viral infection than male patients, but there was no association between patient sex and prescribing an antipsychotic medication. Patients who saw a fee-for-service provider had 4.35 times higher odds (95\% CI 3.31-5.72) of receiving an antibiotic for a viral infection than patients who saw a salaried provider. Conversely, patients with dementia prescribed an antipsychotic medication had $55 \%$ lower odds of having seen a fee-for-service provider than a salaried provider (95\% CI 0.25-0.80) (Table 2).

\section{Laboratory testing}

Between 2014 and 2016, 7356 patients received a PSA test and 2307 patients received a vitamin D test. On average, providers ordered a PSA test for $5 \%$ of the patients in their practice and a vitamin $\mathrm{D}$ test for $1 \%$ of the patients in their practice, annually. There was a median of 4 PSA tests and 1 vitamin D screen per year, per provider. Twenty-four providers (9\%) ordered between 50 and 206 PSA tests a year, testing $16.4 \%$ to $43.6 \%$ of all patients in their practice. Thirty-four providers (14\%) ordered 10 or more vitamin D tests each year. Figure 2 shows that providers contributing to high vitamin D or PSA testing were different. Although PSA testing appeared to be related to the complexity of the patient, vitamin D testing did not appear to be related to patient complexity (Figure 2). 


\section{Research}

A

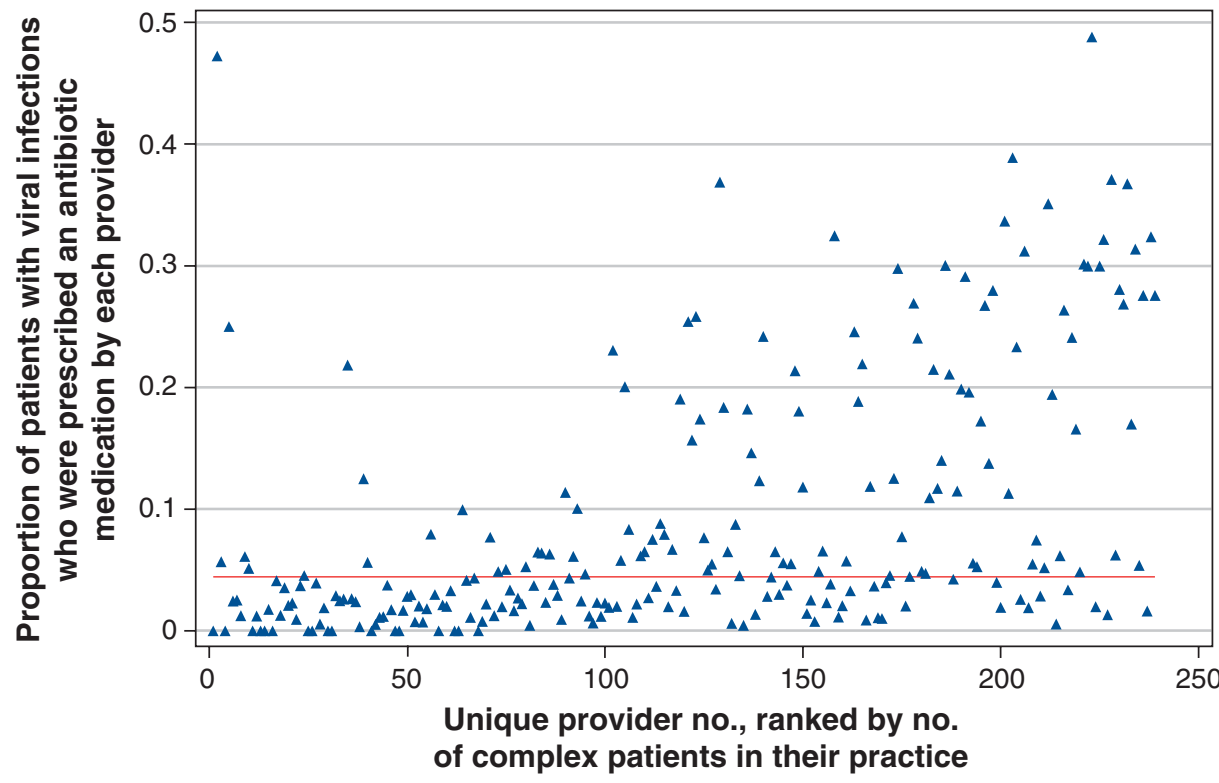

_ Median antibiotic prescribing (4.4\%)

B

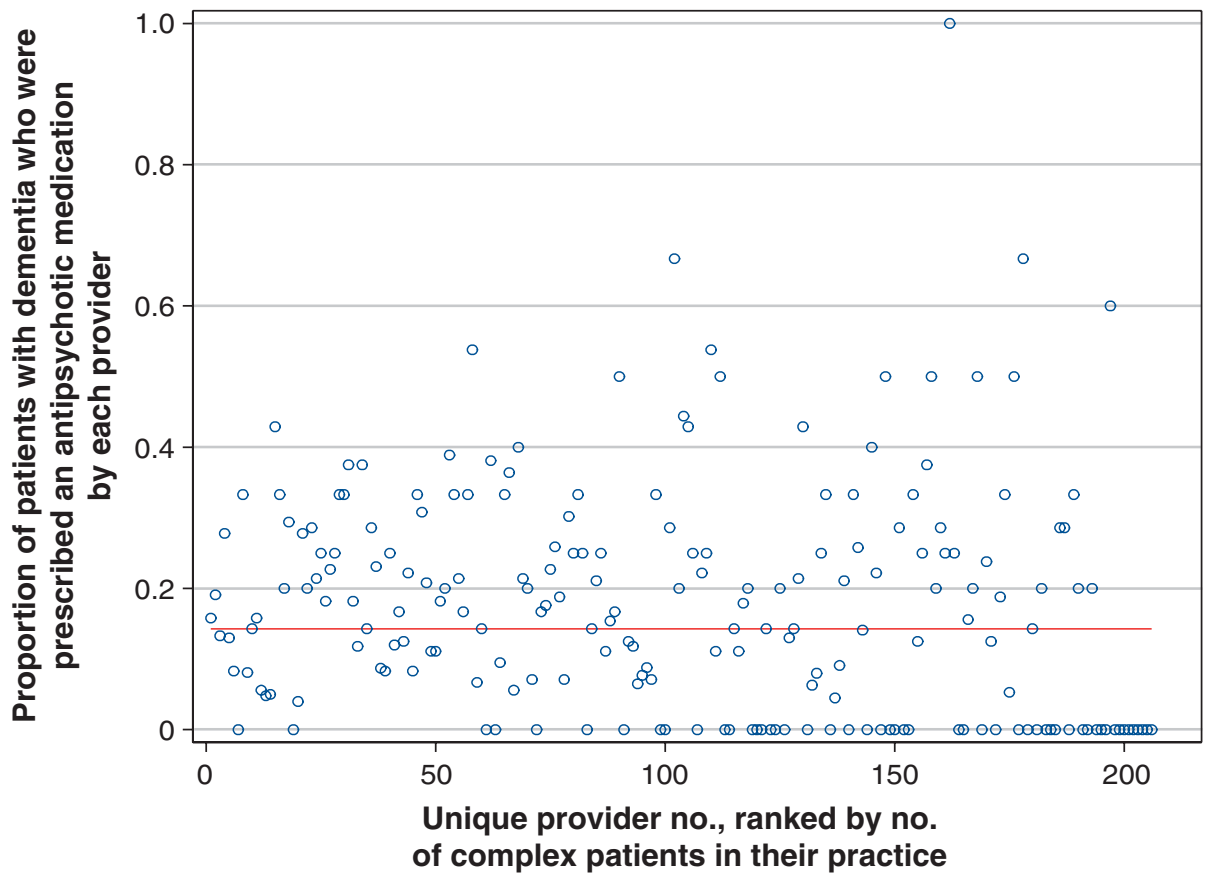

Median antipsychotic prescribing (14.3\%)

Figure 1: Annual prescribing rates for each participating Manitoba Primary Care Research Network provider between 2014 and 2016, ranked by the number of complex patients within the provider's practice. 


\begin{tabular}{|c|c|c|}
\hline \multirow[b]{2}{*}{ Factor } & \multicolumn{2}{|c|}{ Type of prescription; OR $(95 \% \mathrm{Cl})$} \\
\hline & $\begin{array}{l}\text { Antibiotic prescription for } \\
\quad \text { viral infection } \\
n=16742 \text { patients* }\end{array}$ & $\begin{array}{l}\text { Antipsychotic prescription for } \\
\text { treatment of symptoms of } \\
\text { dementia } \\
n=573 \text { patients } \dagger\end{array}$ \\
\hline Patient sex (female v. male) & $1.22(1.15-1.30)$ & $0.97(0.67-1.41)$ \\
\hline Patient age ( $<60 \mathrm{yr}$ v. $\geq 60 \mathrm{yr})$ & $1.19(1.02-1.38)$ & - \\
\hline No. of comorbidities $\ddagger$ ( $\geq 3$ v. 0 ) & $2.02(1.90-2.14)$ & $16.22^{*}(8.4-31.3)$ \\
\hline No. of comorbidities $¥$ ( 1 or 2 v. 0 ) & $1.34(1.28-1.39)$ & $6.48(3.49-12.02)$ \\
\hline $\begin{array}{l}\text { Frequency of office visits } \\
\text { (per } 2 \text { visit increase to the same } \\
\text { primary care provider) }\end{array}$ & $1.48(1.30-1.69)$ & $1.3(0.60-2.75)$ \\
\hline $\begin{array}{l}\text { Funding type } \\
\text { (fee-for-service v. salaried) }\end{array}$ & $4.35(3.31-5.72)$ & $0.45(0.25-0.80)$ \\
\hline Practice location (urban v. rural) & $1.46(0.60-3.57)$ & $1.42(0.45-4.44)$ \\
\hline $\begin{array}{l}\text { Practice size } \\
\text { (<1055 patients v. } \geq 1055 \text { patients })\end{array}$ & $1.14(0.75-1.73)$ & $0.91(0.48-1.73)$ \\
\hline Provider age $(\leq 43$ yr v. $>43$ yr $)$ & $0.77(0.50-1.19)$ & $0.95(0.49-1.82)$ \\
\hline Provider sex (male v. female) & $1.12(0.8-1.59)$ & $1.37(0.87-2.16)$ \\
\hline $\begin{array}{l}\text { No. of encounters per week } \\
(<53 \mathrm{v} . \geq 53)\end{array}$ & $0.96(0.68-1.38)$ & $1.17(0.72-1.91)$ \\
\hline $\begin{array}{l}\text { Note: } \mathrm{Cl}=\text { confidence interval, } \mathrm{OR}=\text { odds ratio } \\
{ }^{*} \text { Out of a total of } 164195 \text { patients. } \\
\text { †Out of a total of } 3372 \text { patients with dementia. } \\
\text { fExcluding a diagnosis of dementia. }\end{array}$ & & \\
\hline
\end{tabular}

Patients who visited a primary care provider more frequently were significantly more likely to have a PSA test (odds ratio [OR] $1.42,95 \% \mathrm{CI} 1.28-1.58$ ) or a vitamin D test (OR $1.63,95 \%$ CI $1.38-1.93)$. Patients who obtained care in a rural practice had 5.75 times higher odds (95\% CI 3.79-8.72) of receiving a PSA test and 3.85 times higher odds (95\% CI 2.06-7.19) of receiving a vitamin D test than patients who visited an urban practice. Provider sex was inversely associated with type of test ordered. Patients who received a PSA test were significantly more likely to have seen a male provider (OR 2.07, 95\% CI 1.37-3.14), whereas patients who received a vitamin $\mathrm{D}$ test were significantly less likely to have seen a male provider (OR 0.43, 95\% CI 0.20-0.93) (Table 3).

\section{Interpretation}

Similar to other studies, this study demonstrated that fewer than $30 \%$ of primary care providers conduct interventions in direct contradiction to Choosing Wisely Canada recommendations. ${ }^{1-5}$ Since the burden of unnecessary testing and treatment is not equally distributed, strategies designed to reduce unnecessary care could target specific provider and patient groups. Our modelling showed that each of the 4 testing and prescribing recommendations we asssessed were associated with different provider and patient characteristics. For example, initiatives to reduce unnecessary antibiotic prescribing could focus on fee-for-service providers, while antipsychotic prescribing initiatives could target salaried providers.

In our study, prescribing an antibiotic for a viral infection was the most common potentially unnecessary treatment. We found that $29 \%$ of providers regularly prescribe antibiotics for a viral infection. Similar to other studies, we found antibiotic prescribing for viral infections and antipsychotic prescribing to patients diagnosed with dementia was more likely to occur among patients with 3 or more comorbidities. ${ }^{14-16,26-29}$ Antibiotic prescribing among patients with comorbidities may be related to the suspicion of a secondary bacterial infection following clinical assessment. ${ }^{26,27}$ On average, antipsychotics were prescribed to $14 \%$ of patients with dementia in a practice. This percentage is lower than in a study of patients living in Alberta long-term care facilities, in which $20 \%$ of dementia patients were prescribed an antipsychotic. ${ }^{28}$ Consistent with a recent meta-analysis, our study demonstrated that primary care provider remuneration can affect treatment patterns. ${ }^{30}$ Heckman and colleagues found that patients diagnosed with Parkinson disease were more likely to be prescribed an antipsychotic medication if they were medically complex. ${ }^{29}$ If appropriately monitored for patient benefit and harms, antipsychotic prescriptions may be warranted for uncontrolled agitation and severe psychosis symptoms that are dangerous or causing significant distress to the patient. ${ }^{14-16,31}$

In our study, fewer than $15 \%$ of providers contributed to the vast majority of PSA and vitamin D tests. A recent 


\section{Research}

A

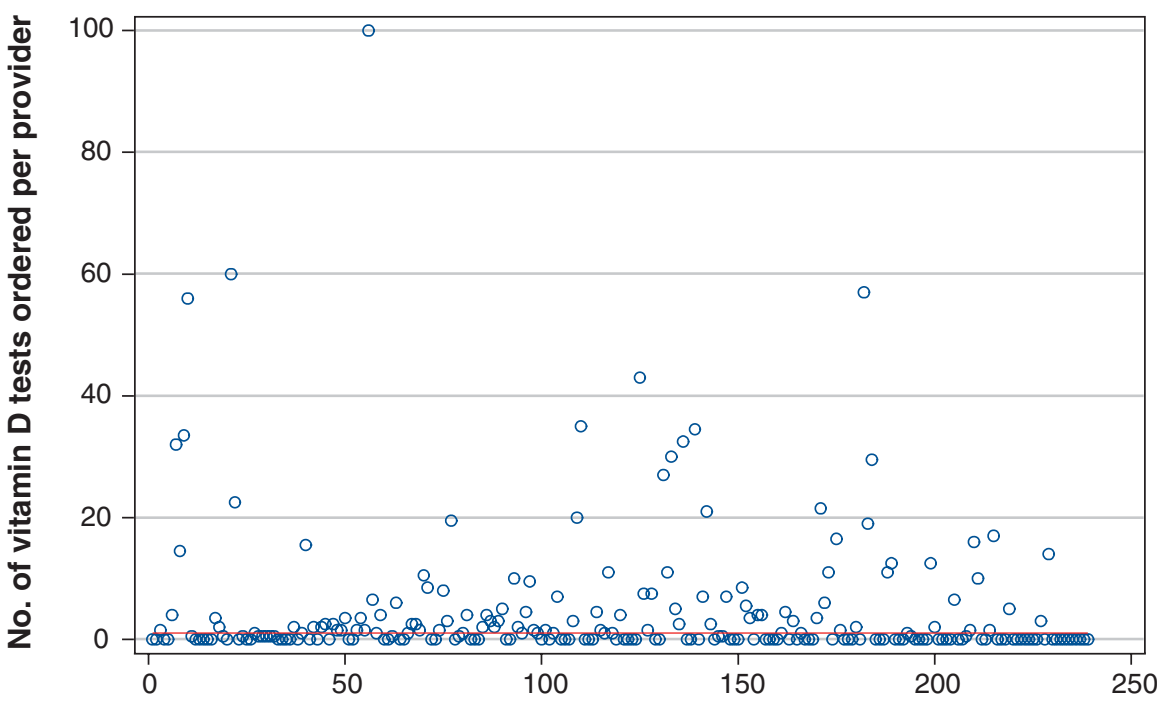

Unique provider no., ranked by no. of complex patients in their practice

Median (1 vitamin D test)

B

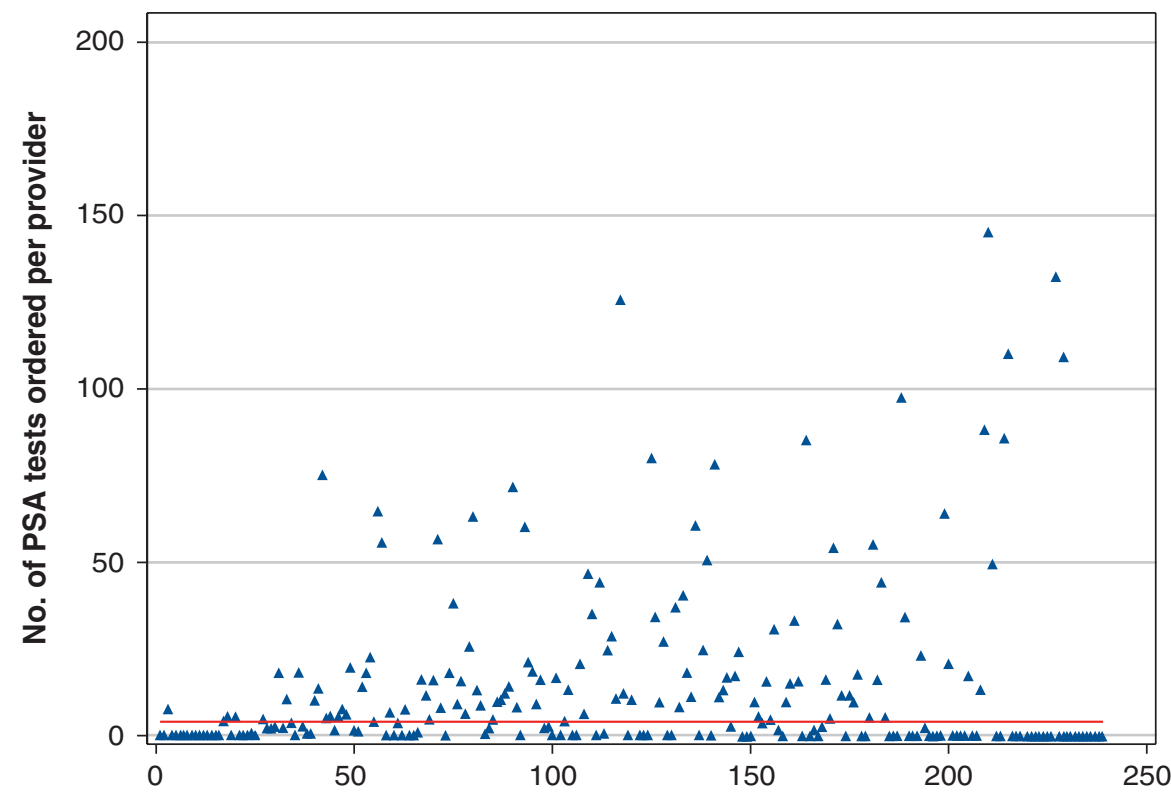

Unique provider no., ranked by no. of complex patients in their practice

Median (4 PSA tests)

Figure 2: Annual number of screening tests ordered by each Manitoba Primary Care Research Network participating provider $(n=239)$ between 2014 and 2016, ranked by the number of complex patients within the provider's practice. PSA $=$ prostatespecific antigen. 


\begin{tabular}{|c|c|c|}
\hline \multirow[b]{2}{*}{ Factor } & \multicolumn{2}{|c|}{ Type of test; OR $(95 \% \mathrm{Cl})$} \\
\hline & $\begin{array}{l}\text { Vitamin D test } \\
\quad n=2307\end{array}$ & $\begin{array}{l}\text { PSA test } \\
n=7356\end{array}$ \\
\hline Patient sex (female v. male) & $1.34(1.05-1.71)$ & - \\
\hline Patient age, yr & $1.73^{*}(1.00-2.99)$ & $3.48 \dagger(3.16-3.83)$ \\
\hline No. of comorbidities ( $\geq 3$ v. 0 ) & $1.39(1.18-1.64)$ & $1.31(1.20-1.44)$ \\
\hline No. of comorbidities ( 1 or 2 v. 0 ) & $1.40(1.26-1.57)$ & $1.71(1.61-1.81)$ \\
\hline $\begin{array}{l}\text { Frequency of office visits } \\
\text { (per } 2 \text { visits to the same primary care provider) }\end{array}$ & $1.63(1.38-1.93)$ & $1.42(1.28-1.58)$ \\
\hline Funding type (salaried v. fee-for-service) & $2.20(0.87-5.59)$ & $0.85(0.58-1.26)$ \\
\hline Practice location (rural v. urban) & $3.85(2.06-7.19)$ & $5.75 \dagger(3.79-8.72)$ \\
\hline $\begin{array}{l}\text { Practice size } \\
\text { ( } \geq 1055 \text { patients } v .<1055 \text { patients })\end{array}$ & $1.08(0.45-2.63)$ & $2.15(1.07-4.30)$ \\
\hline Provider age ( $\leq 43$ yr v. $>43$ yr) & $0.83(0.18-3.78)$ & $0.61(0.20-1.85)$ \\
\hline Provider sex (male v. female) & $0.43(0.20-0.93)$ & $2.07(1.37-3.14)$ \\
\hline No. of encounters per week $(<53 \mathrm{v} . \geq 53)$ & $1.41(0.73-2.72)$ & $1.52(0.42-1.04)$ \\
\hline \multicolumn{3}{|c|}{$\begin{array}{l}\text { Note: } \mathrm{OR}=\text { odds ratio, PSA }=\text { prostate-specific antigen. } \\
\text { *Per } 10 \text {-yr increase in patient age. } \\
\text { †Patients aged }<55 \text { yr or }>70 \mathrm{yr} \text { (weak recommendation to screen) v. patients aged } 55-70 \mathrm{yr} \text { (screening not } \\
\text { recommended). }\end{array}$} \\
\hline
\end{tabular}

unpublished internal report on vitamin D testing in Manitoba noted that approximately $60 \%$ of the vitamin $\mathrm{D}$ tests analyzed had no apparent medical indication. ${ }^{32}$ In northern climates vitamin D supplementation is routinely recommended., ${ }^{6,21-25}$ Nevertheless, we found an annual average rate of vitamin D testing of 4.83 screens per practice per year. This is similar to administrative data in Manitoba that show that a relatively small number of physicians ordered the vast majority of vitamin $\mathrm{D}$ tests. ${ }^{32}$ This pattern is also apparent for PSA testing, where a small minority of providers account for most PSA testing above the $5 \%$ median testing rates. We found that PSA and vitamin D testing was higher among patients who visited the primary care office more frequently. Providers ordering PSA tests for approximately $5 \%$ of the patients in their practice are probably assessing for prostate cancer among symptomatic males, consistent with existing evidence. ${ }^{18-20}$ Interestingly, provider sex was associated with testing. Male providers were significantly more likely to order a PSA test but less likely to order a vitamin D test.

\section{Limitations}

While this study represents a comprehensive sample of primary care appointments in Manitoba (for 15\% of the Manitoba population), the Manitoba Primary Care Research Network database does not include all primary care encounters. The Manitoba Primary Care Research Network does not include encounters from remote communities in Manitoba, specifically on-reserve First Nation populations. Depending on patient characteristics within a practice, rates of prescribing and testing may be higher or lower than the target rates derived from this study. The EMR data used in this study did not include measures of provider attitudes to the Choosing Wisely Canada recommendations or the number of years a provider had practised medicine. It is possible that some providers did not agree with the Choosing Wisely Canada recommendations or had different interpretations of the supporting evidence. We used structured EMR data to identify patient diagnoses, prescribing details and testing rates, which may under- or over-capture some diagnoses. This study did not assess unstructured text notes of the physician that may have provided an explanation for the prescribing and testing practices we assessed. Adding analysis of unstructured EMR free-text notes such as encounter notes would provide clinical context of the patient encounter, including symptoms presented at the appointment, that may have led to an intervention. In Manitoba, EMR records contain 1 diagnosis code (ICD-9-CM) per visit to a health care provider, for the purpose of payment to a single insurer (Manitoba Health) in both fee-for-service and salaried environments. We assumed that the diagnosis chosen for billing was accurate. Our study may have undercaptured some details regarding clinical presentation. The reliance on structured EMR data may have introduced an ascertainment bias. EMR data are known to have some gaps in terms of data completeness, ${ }^{33,34}$ but using clinical data from EMRs has been shown to be valid for use in diagnoses of acute presentations. ${ }^{35-37}$

\section{Conclusion}

Fewer than $30 \%$ of primary care providers contribute to unnecessary care. Rates of potential overprescribing and overtesting are associated with different patient and practice factors that are dependent on the intervention. The association 
between remuneration and provider prescribing practices should be explored, considering implications for patient care. Additionally, the elevated rates of PSA testing among male providers and vitamin $\mathrm{D}$ testing among female providers may be an important target for reduction in unnecessary testing. While traditional approaches to improvement aim to improve practice patterns across the population, our findings suggest that quality improvement initiatives targeted at providers who are contributing to unnecessary interventions may be more beneficial.

\section{References}

1. National bealth expenditure trends, 1975 to 2016. Ottawa: Canadian Institute for Health Information; 2016. Available: https:/www.cihi.ca/sites/default/files/ document/nhex-trends-narrative-report_2016_en.pdf (accessed 2017 Aug. 22).

2. Provincial and territorial ranking: health. Ottawa: The Conference Board of Canada; 2015. Available: https://www.conferenceboard.ca/hcp/Provincial/ Health.aspx (accessed 2017 Aug. 22).

3. Institute of Medicine. Best care at lower cost: the path to continuously learning bealth care in America. Washington (DC): The National Academies Press; 2013. doi: $10.17226 / 13444$.

4. Lyu H, Xu T, Brotman D, et al. Overtreatment in the United States. PLoS One 2017;12:e181970.

5. Facts about unnecessary tests, treatments, and procedures [about]. Choosing Wisely Canada. Available: https://choosingwiselycanada.org/about/ (accessed 2018 Aug. 22).

6. College of Family Physicians of Canada. Thirteen things physicians and patients should question. Choosing Wisely Canada; (updated January 2018). Available: https://choosingwiselycanada.org/family-medicine/ (accessed 2018 Aug. 28).

7. Canadian Geriatrics Society. Five things physicians and patients should question. Choosing Wisely Canada; (updated June 2017). Available: https:// choosingwiselycanada.org/geriatrics/ (accessed 2018 Aug. 28).

8. Chow AW, Benninger MS, Brook I, et al.; Infectious Diseases Society of America. IDSA clinical practice guideline for acute bacterial rhinosinusitis in children and adults. Clin Infect Dis 2012;54:e72-112.

9. Smith SS, Evans CT, Tan BK, et al. National burden of antibiotic use for adult rhinosinusitis. 7 Allergy Clin Immunol 2013;132:1230-2.

10. Desrosiers M, Evans GA, Keith PL, et al. Canadian clinical practice guidelines for acute and chronic rhinosinusitis. Allergy Asthma Clin Immunol 2011;7:2.

11. Low D. Reducing antibiotic use in influenza: challenges and rewards. Clin Microbiol Infect 2008;14:298-306.

12. Hirschmann JV. Antibiotics for common respiratory tract infections in adults. Arch Intern Med 2002;162:256-64.

13. Madhusoodanan S, Shah P, Brenner R, et al. Pharmacological treatment of the psychosis of Alzheimer's disease: what it the best approach? CNS Drugs 2007;21:101-15.

14. Gill SS, Bronskill SE, Normand SL, et al. Antipsychotic drug use and mortality in older adults with dementia. Ann Intern Med 2007;146:775-86.

15. Lee PE, Gill SS, Freedman M, et al. Atypical antipsychotic drugs in the treatment of behavioural and psychological symptoms of dementia: systematic review. $B M 7$ 2004;329:75.

16. Rochon PA, Normand SL, Gomes T, et al. Antipsychotic therapy and shortterm serious events in older adults with dementia. Arch Intern Med 2008; 168:1090-6.

17. LeBlanc E, Chou R, Zakher B, et al. Screening for vitamin D deficiency: systematic review for the U.S. Prevention Services Task Force Recommendation. Report No. 13-05183-EF-1. Rockville (MD): Agency for Healthcare Research and Quality (US); November 2014.

18. Bell N, Connor Gorber S, Shane A, et al.; Canadian Task Force on Preventive Health Care. Recommendations on screening for prostate cancer with the prostate-specific antigen test. CMA7 2014;186:1225-34.

19. ABIM Foundation. The PSA blood test for prostate cancer: When men need it - and when they don't. Choosing Wisely. Available: www.choosingwisely. org/patient-resources/psa-test-for-prostate-cancer/ (accessed 2017 Aug. 13).

20. van Leeuwen PJ, Connolly D, Gavin A, et al. Prostate cancer mortality in screen and clinically detected prostate cancer: estimating the screening benefit. Eur 7 Cancer 2010;46:377-83.

21. Hanley DA, Cranney A, Jones G, et al.; Guidelines Committee of the Scientific Advisory Council of Osteoporosis Canada. Vitamin D in adult health and disease: a review and guideline statement from Osteoporosis Canada (summary). CMAf 2010;182:1315-9.

22. Vitamin D testing in the general population: a review of the clinical costeffectiveness and guidelines - Rapid response report: summary with critical appraisal. Ottawa: Canadian Agency for Drugs and Technologies in Health; 2015 Jan. 15. Available: https://www.ncbi.nlm.nih.gov/books/NBK274106/ (accessed 2015 Aug. 14).

23. Souberbielle JC, Courbebaisse M, Cormier C, et al. When should we measure vitamin D concentration in clinical practice? Scand 7 Clin Lab Invest Suppl 2012;243:129-35.

24. New vitamin $\mathrm{D}(25(\mathrm{OH}) \mathrm{D})$ ordering criteria and requisition [clinical practical change]. Choosing Wisely Manitoba; 2016 Jan. 21 (effective 2016 Feb. 16). Available: https://chimb.ca/documents/01-18-16-cwm-clinical-practice -change-vit-d-final.pdf (accessed 2018 Oct. 2).

25. Calvo MS, Whiting SJ. Prevalence of vitamin D insufficiency in Canada and the United States: importance of health status and efficacy of current food fortification and dietary supplement use. Nutr Rev 2003;61:107-13.

26. Singer A, Fanella S, Kosowan L, et al. Informing antimicrobial stewardship: factors associated with inappropriate prescribing in primary care. Fam Pract 2018;35:455-60.

27. Serna MC, Real J, Ribes E, et al. Factors determining antibiotic prescription in primary care [article in Spanish]. Enferm Infecc Microbiol Clin 2011;29: 193-200.

28. Khurshed F, Metes D, Aku A, et al. Data impact challenge answer submission template. Toronto: Canada Health Infoway. Available: http://imaginenationchallenge. ca/wp-content/uploads/2015/09/Alberta-Data-Geeks-6d.pdf (accessed 2018 Oct. 2).

29. Heckman GA, Crizzle AM, Chen J, et al. Clinical complexity and use of antipsychotics and restraints in long-term care residents with Parkinson's disease. 7 Parkinsons Dis 2017;7:103-15.

30. Yuan B, He L, Meng Q, et al. Payment methods for outpatient care facilities. Cochrane Database Syst Rev 2017;3:CD011153.

31. Brooks M. New practice guidelines on antipsychotic use in dementia. New York: Medscape, LLC; 2016 May 3. Available: www.medscape.com/viewarticle/ 862795 (accessed 2017 Aug. 22).

32. Project closure report: appropriate vitamin D testing $25(\mathrm{OH})$. Winnipeg: George \& Fay Yee Centre for Healthcare Innovation; 2016.

33. Singer A, Kroeker AL, Yakubovich S, et al. Data quality of electronic medical records in Manitoba: Do problem lists reflect chronic disease as defined by prescriptions? Can Fam Physician 2017;63:382-9.

34. Singer A, Yakubovich S, Kroeker AL, et al. Data quality of electronic medical records in Manitoba: Do problem lists accurately reflect chronic disease billing diagnoses? 7 Am Med Inform Assoc 2016;23:1107-12.

35. Katz A, Halas G, Dillon M, et al. Describing the content of primary care: limitations of Canadian billing data. BMC Fam Pract 2012;13:7.

36. Kern DM, Davis J, Williams SA, et al. Validation of an administrative claimsbased diagnostic code for pneumonia in a US-based commercially insured COPD population. Int 7 Chron Obstruct Pulmon Dis 2015;10:1417-25.

37. Mangione-Smith R, Wong L, Elliott MN, et al. Measuring the quality of antibiotic prescribing for upper respiratory infections and bronchitis in 5 health plans. Arch Pediatr Adolesc Med 2005;159:751-7.

Affiliations: Departments of Family Medicine (Singer, Kosowan, Katz, Jolin-Dahel, Appel) and Community Health Sciences (Katz, Lix), Max Rady College of Medicine, Rady Faculty of Health Sciences, University of Manitoba; Manitoba Primary Care Research Network (Singer); Manitoba Centre for Health Policy (Katz), Winnipeg, Man.; Centre Medical Seine (Jolin-Dahel), Ste. Anne, Man.; Seven Oaks Hospital (Appel), Winnipeg, Man.

Contributors: Alexander Singer and Leanne Kosowan conceived and designed the study and acquired and analzyed the data. All authors contributed to interpreting the data, drafting the article and revising it critically for important intellectual content. All authors gave final approval of the version to be published and agree to act as guarantors of the work (ensuring that questions related to any part of the work are appropriately investigated and resolved).

Funding: The Manitoba Medical Service Foundation provided funding for this study. The Manitoba Primary Care Research Network is supported with funding from the Department of Family Medicine at the University of Manitoba. The Canadian Primary Care Sentinel Surveillance Network received funding by a grant from the Public Health Agency of Canada in partnership with the College of Family Physicians of Canada and is currently supported by Queen's University.

Acknowledgements: The authors would like to acknowledge William Peeler, Sylvia Froese, Lisa Labine, Albert Mota and Elissa Abrams for their contribution to this article.

Supplemental information: For reviewer comments and the original submission of this manuscript, please see www.cmajopen.ca/content/6/4/ E603/suppl/DC1. 